\title{
Surrounding Rock Deformation Mechanism and Control Technology for Gob-Side Entry Retaining with Fully Mechanized Gangue Backfilling Mining: A Case Study
}

\author{
Peng Gong, ${ }^{1}$ Zhanguo Ma, ${ }^{1}$ Ray Ruichong Zhang, ${ }^{2}$ \\ Xiaoyan Ni, ${ }^{1}$ Fei Liu, ${ }^{1}$ and Zhimin Huang ${ }^{1}$ \\ ${ }^{1}$ State Key Laboratory for Geomechanics and Deep Underground Engineering, School of Mechanics and Civil Engineering, \\ School of Science, China University of Mining \& Technology, Xuzhou, Jiangsu 221116, China \\ ${ }^{2}$ Department of Mechanical Engineering, Colorado School of Mines, Golden, CO 80401, USA \\ Correspondence should be addressed to Zhanguo Ma; zgma@cumt.edu.cn
}

Received 17 December 2016; Accepted 7 March 2017; Published 14 May 2017

Academic Editor: Yuri S. Karinski

Copyright $\odot 2017$ Peng Gong et al. This is an open access article distributed under the Creative Commons Attribution License, which permits unrestricted use, distribution, and reproduction in any medium, provided the original work is properly cited.

\begin{abstract}
To counter the technical difficulties faced by gob-side entry retaining (GER) under multiple complex mining geological conditions in China, this paper introduces a GER method with fully mechanized gangue backfilling mining. A similar materials simulation experiment was conducted to simulate the gob-backfilled GER process by using the similar model test system containing an independently developed horizontal pushing load device. The experimental results show that the compaction speed of the backfilling area (BFA) can be improved, and the main roof subsidence can be reduced by increasing the horizontal pushing load and reducing the attenuation rate of the stress in BFA. The designed roadside backfill body (RBB) containing a flexible cushion is adaptive to the given deformation of the main roof, thus reducing the stress concentration of the RBB. The field test results show that when a $2 \mathrm{MPa}$ horizontal pushing load is exerted in the BFA, arranging a $200 \mathrm{~mm}$ high-water-material flexible cushion can cause the BFA to swiftly change to the compaction stage. After stabilized deformation, the roadway section satisfies the design and application requirements. The feasibility and rationality of the GER with the fully mechanized gangue backfilling mining are proved, providing a safe, efficient, and environmentally friendly mining method without using a coal pillar.
\end{abstract}

\section{Introduction}

In gob-side entry retaining (GER) of underground coal seam mining, the headgate (entry 2 in front of the active panel $\# 1$ ) of the current mining panel (panel \#1) is retained by constructing the roadside backfill body (RBB) and serves as the tailgate (entry 2 behind the active panel \#1) to the subsequent adjacent panel (panel \#2) $[1,2]$ (Figure 1). The gangue backfilling GER is a mining technology based on gobbackfilled adaptive to multiple complex mining geological conditions without a coal pillar. The main advantages of this technology are as follows. (1) It overcomes the technological bottleneck of GER under deep multiple complex location conditions, providing a safe, efficient, and environmental mining method without a coal pillar, thus paving a solid way for the promotion of GER. (2) The pressure on the working face is reduced, thus avoiding the impact hazard due to roof breaking and coal pillar instability $[3,4]$, in turn facilitating entry retaining in a high-stress large-section roadway. (3) The technology utilizes the gangues piling on the ground to backfill the gob, thus resolving the safety problem due to gangue piling on the ground and avoiding the destruction of the underground water system due to coal mining to realize environmental protection and recovery. (4) One roadway can be utilized twice, thus reducing the roadway driveage ratio and mitigating the mining-excavation relay conflicts. (5) Conventionally, on a fully mechanized mining face, $8-30 \mathrm{~m}$ coal pillars are set up to ensure the safe use of neighboring roadways, which results in serious wastage of coal resources. Moreover, under the condition of thick 


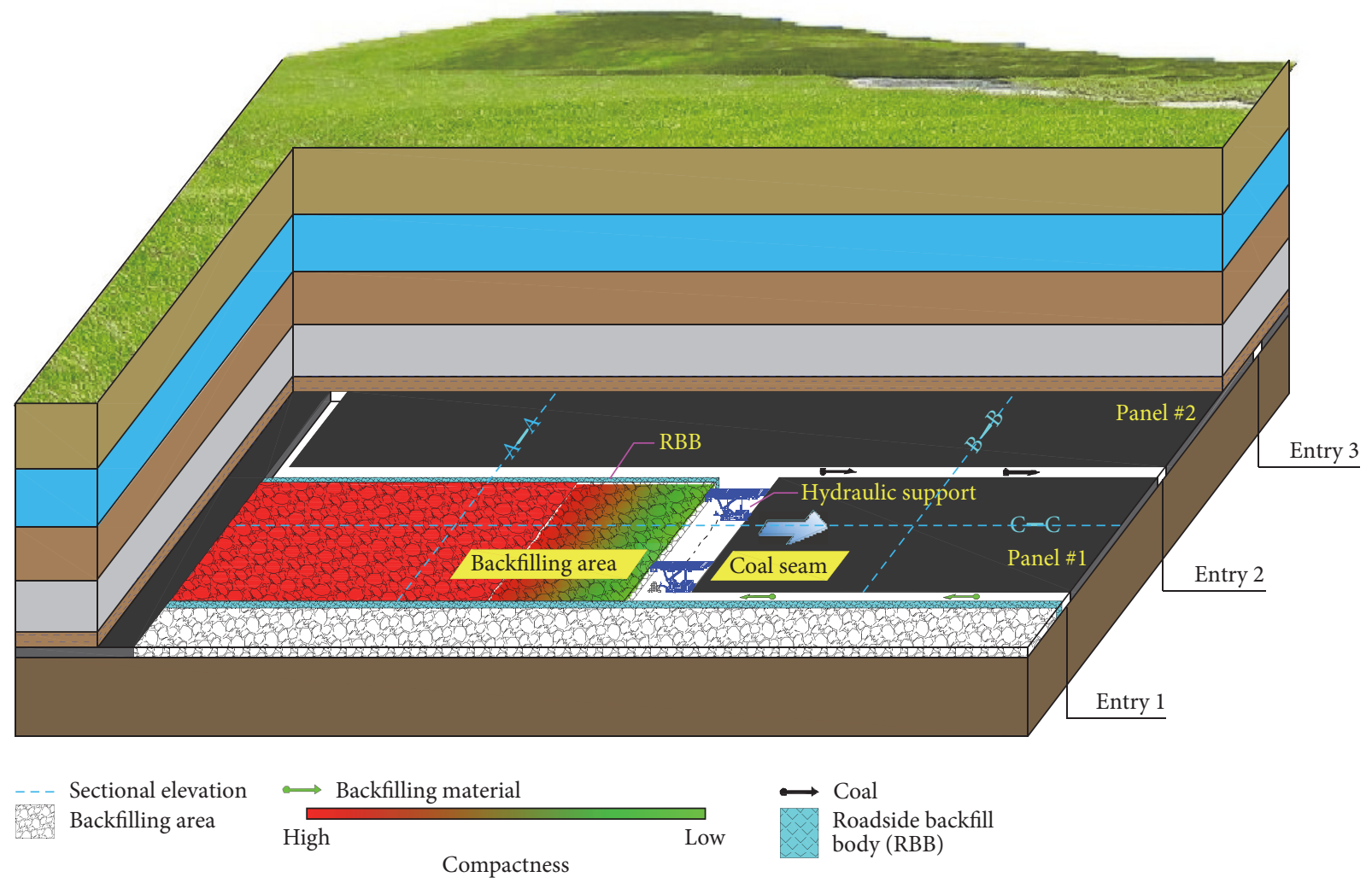

FIGURE 1: Working face layout of GER with fully mechanized gangue backfilling mining.

coal seams, the resource loss due to sectional coal pillars accounts for over $50 \%$ of the coal loss for the whole mine. In contrast, GER uses RBB to replace the coal pillars for roadway maintenance, thus avoiding waste of coal pillar resources and improving coal recovery rate. (6) Y-shaped ventilation is realized, solving the problem of gas accumulation at the corner of the working face. Owing to the advantages of simple layout and good economic performance of the $\mathrm{u}$ shape ventilation method, it is used by most working faces in underground fully mechanized coal mining. As the mining gets deeper, the gas emission of the high-gas working face reaches $90-120 \mathrm{~m}^{3} / \mathrm{min}$, complicating the treatment of the gas at the corner of the working faces by using the $\mathrm{u}$ shape ventilation [5]. In contrast, the Y-shaped ventilation method at GER working face uses a ventilation system layout consisting of two intake entries and one return airway; that is, entries 1 and 2 at the front of active panel \#2 serve as intake entries, and entry 2 behind active panel \#1 serves as a return airway. In this ventilation method, the air leakage in the gob primarily flows to the retained entry, fundamentally solving the problem of gas accumulation at the corner of the working faces.

Since the 1950s, the world's major coal production countries, including the United Kingdom, German, Poland, Russia, and China, started exploring the GER technology [6]. Currently, research on GER conducted by many scholars worldwide is primarily based on the mining conditions of the roof managed using the caving method, focusing on roof-structure optimization, roadside support form, roadside support resistance, and entry-in reinforced support parameter design. The existing field-measurement results show that in such GER methods in which the roof is managed using caving method, as the working face advances, the rotational deformation toward the gob side occurs to the roof, resulting in the increase in the support force of the RBB. When the early strengths of the reinforced support measures in the roadway and the RBB are able to provide adequate support resistance, the key strata of the roof reach the bending moment limit around the $\mathrm{RBB}$ edge, and the key blocks of the retained entry roof are sheared down along the outer side of the $\mathrm{RBB}$ [7]. The shearing down of the main roof can reduce its hanging length at the gob side, reducing the additional load exerted on the RBB by the roof, hence realizing the purpose of reducing roadway stress concentration and impact hazard, and improving GER success rate. Therefore, the determination of whether the key block of the roof can be safely sheared down along the outer side of RBB is crucial for the success of GER with roof caving.

Therefore, many scholars and engineers conducted research in fields for improving the material strength of $\mathrm{RBB}$, optimizing the entry-in support parameters and artificial intervening roof caving $[8,9]$; positive results have been obtained. Owing to disadvantages such as small retained entry section, poor gob isolation effects, inflammability, intensive labor, slow auxiliary transport, and construction speed [10], early roadside support forms, such as timber cribs 
and walls, are no longer applicable to the requirement of GER in underground fully mechanized coal mining. Bai et al. [11] developed high-water quick-setting materials and pasty materials as new RBB materials, the advantages of which include high-support resistance, quick resistance-increase speed, being shrinkable (to a certain extent), good roadway maintenance performance, mechanized integral construction, and good enclosure of the gob. In [12, 13], it was assumed that the retained entry height has a major effect on the stability of the RBB, and a method was proposed for designing an appropriate-width RBB under different mining heights and roof lithology conditions. Based on the stage characteristics of GER deformation, a method combining entry-in basic support with reinforced support was used in $[14,15]$, which is successful in GER practice for easy caving and medium caving roofs. In $[16,17]$, artificial forced caving using a presplitting blasting method was attempted, and GER was completed with a hard roof of a thin or medium thick coal seam. Design cases of roof presplitting heights, angles, and blasting bore pitch were provided.

Based on the theoretical and technological research results, we basically mastered the mine pressure law of GER in thin and medium thick coal seams under simple conditions. In addition, applications under single complex mining geological condition, such as deep mine or the working faces of fully mechanized top coal caving, were explored [18, 19]. However, research on the GER technology at large-height working faces under high-stress multiple complex geological conditions is limited; this is still a challenge limiting GER development [20].

The gradual maturity of backfill mining technology provides necessary conditions for the GER development [21, 22]. In China, there are over 1600 gangue piles occupying land area of $1.5 \times 10^{8} \mathrm{~m}^{2}$. In Shandong Province alone, there are 136 working faces, and 17.20 million tons of accumulativefilled gangues [23]. Field monitoring results show that the lead abutment pressure peak value of backfill mining is only about $20 \%$ that of the nonbackfill mining, and the maximum roadway converging deformation area is only about $30 \%$ that of the nonbackfill mining [24]. This article proposes an innovative GER method, generally applicable to multiple complex mining geological conditions, by combining underground backfill mining technology with GER technology.

\section{Test System and Key Parameter Design}

2.1. Key Problems in Gangue Backfilling GER. In GER methods in which roofs are managed using the caving method, the movement of the roof can be divided into three stages by time [25]: early stage activities (Stage I), transitional stage activities (Stage II), and late stage activities (Stage III), as shown in Figure 2.

In the early stage, with the mining on the working face, a hanging roof is developed at the gob behind the working face, and the immediate roof strata slumps under the effect of gravity. Owing to the support of the lead solid coal and $\mathrm{RBB}$, the deformation of the main roof is minor. Therefore, the deformation of the RBB is minor at this stage.

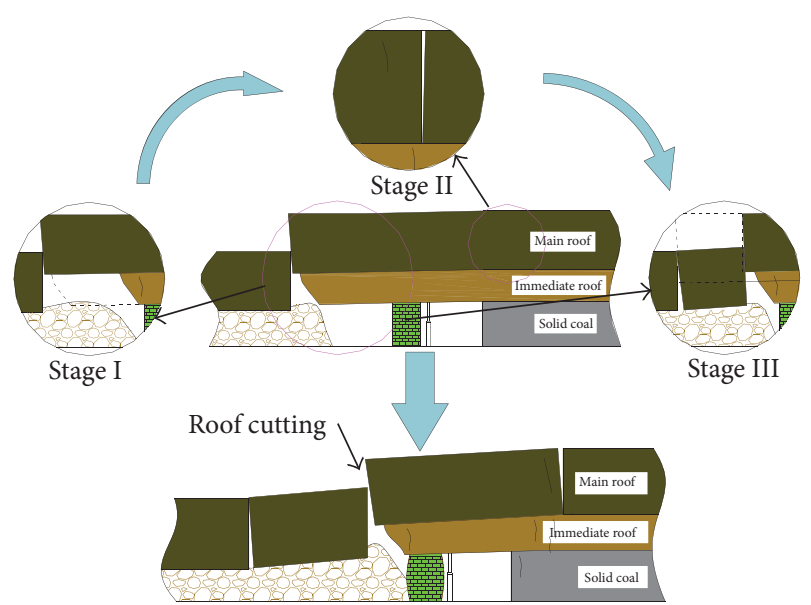

FIGURE 2: Structural characteristics of the GER roof by the caving method.

In the transition stage, as the working face advances, obvious rotational deformation occurs to the main roof, far away from the working face, and the RBB shows high degree of deformation. The support stress transfers toward the deep part of the roadside solid coal, and elastic energy accumulates at the roof. When the tensile stress in the bending of the main roof reaches its limit, a fault occurs in the main roof of the deep solid coal. At this stage, the compression amount of the RBB reaches its maximum. Field test results show that the roof deformation of the GER at this stage accounts for about $70 \%$ of the total deformation.

In the late stage, the main roof hanging at the gob side shears down under the combined effects of the strong support of the RBB and the entry-in reinforced support. After the roadside roof cutting is completed, the compression amount of the RBB and the converging deformation of the GER remain stabilized.

However, under complex mining geological conditions, such as large mining height, high roof cutting difficulty and frequent rock burst accidents result in a low GER success rate. A coal-pillarless mining pattern that is impact-, water-rupture-, and subsidence-resistant can be obtained using the gangue backfilling GER method. Owing to the support of the gangues in the BFA, the main roof only has bending subsidence. Compared to conventional GER, the stress environment in the BFA, roof, and roadway have fundamental differences. Therefore, the success of gangues backfilling GER depends on research of the following key problems.

(1) Stress on the Granular Gangues in the BFA. Under the impact load effect of the pushing device, the BFA is compacted. Owing to the flowability of gangues in the BFA, the granular gangues will naturally fall back to pile up after the pushing device is withdrawn. As the main bearing structure of the roof, the deformation law and stress distribution characteristics of the backfilling granular gangues are highly different from those of the conventional GER technology. 


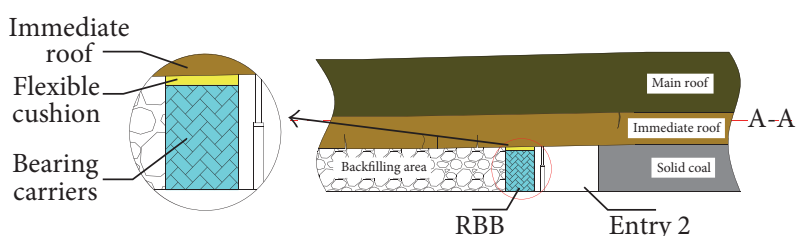

FIGURE 3: RBB structure of GER with fully mechanized backfilling mining.

Therefore, the research of the stress distribution characteristics of the BFA under different degrees of pushing load effects is the basis for analyzing the activity law of the roof strata and stress environment of the RBB and is the basis for designing the backfilling process parameter.

(2) Roof Strata Deformation Law. Owing to uneven distribution of compaction in the BFA, uneven subsidence occurs in the roof from the solid coal to the BFA. The research of the deformation law and fracture forms of the roof strata plays an important role in the RBB parameter design.

(3) RBB Stability. Stability of RBB is the most direct reflection of the GER performance. Therefore, the design principle of $\mathrm{RBB}$ for the gangue backfilling GER must be summarized by analyzing test results. Based on the mine pressure law measured in the field from gangue backfilling coal mining, this article proposes a soft-hard combined RBB solution (Figure 3). The rationality of the new RBB design solution must be further discussed.

2.2. Design of Test System. To more accurately reflect the actual mining environment, this article performs a laboratory similar-material simulation experiment to research the surrounding rock deformation mechanism of fully mechanized gangue backfilling GER [26-28]. As the existing test device cannot simulate the horizontal pushing load, the current study designed a backfilling mining GER test system that can push-press horizontally (Figure 4). The system primarily comprises a water power loading system, a hydraulic horizontal pressing system, a stress monitoring system, and a digital displacement measurement system.

The water power loading system comprises a water pressure loading console, water pipe, pressurizing water bag, and water bag baffle and can evenly apply a vertical load to the top of the model.

The hydraulic pressing system comprises the console, oil pipe, pressing mechanism, hydrocylinder, base, and spout and can push-press the BFA horizontally.

The stress monitoring system comprises pressure sensors embedded in the model and a high speed static strain acquisition instrument. It can monitor the stress change in the strata and the BFA during the processes of mining, backfilling, and pushing.

The digital displacement measurement system comprises a high-resolution digital camera and PhotoInfor digitalimage-processing software and can analyze the change of displacement field of the model throughout the mining process.

\subsection{Design of Key Parameters of Backfilling GER Test}

2.3.1. Mining Geological Conditions. The test mine is in the Shandong Province of China. The ground elevation of the test zone is $+32.93-+33.08 \mathrm{~m}$; the underground elevation is $-642--636 \mathrm{~m}$; the coal seam strike approximates East-West $(\mathrm{E}-\mathrm{W})$, trending south; true dip is at $0^{\circ}-3^{\circ}$; and monoclinal structure is high in the north and low in the south. The expected coal seam angle in the tunneling direction is $0^{\circ}-3^{\circ}$. The main mining coal seam is Seam $3_{\text {lower }}$, coefficient of hardness $f=1-2$, thickness is at $3.08-4.10 \mathrm{~m}$, and mean thickness is $3.5 \mathrm{~m}$. Seam $3_{\text {lower }}$ of the coal floor consists of mudstone and siltstone, and Seam $3_{\text {lower }}$ of the coal roof consists of mudstone and siltstone. The hardness coefficient of the mudstone and siltstone $f=4-6$, the relative emission of $\mathrm{CO}_{2}$ of Seam $3_{\text {lower }}$ is $0.417 \mathrm{~m}^{3} / \mathrm{t}$, the relative gas emission is $0.25 \mathrm{~m}^{3} / \mathrm{t}$, the explosion index of the coal seam is $41.15 \%$, and the period of coal spontaneous combustion is 3-6 months. The strata geological log is as shown in Figure 5.

2.3.2. Similar Model Test Design. In the research of the physical process or mechanical property of various phenomena, physical-quantity similarity primarily refers to geometric, kinematic, and dynamic similarities. Therefore, between Model $\left({ }^{\prime}\right)$ and prototype $\left({ }^{\prime \prime}\right)$, the following six basic similarity conditions are satisfied.

(1) Geometric Similarity. The dimensions of the model and prototype satisfy $l_{1}^{\prime} / l_{1}^{\prime \prime}=l_{2}^{\prime} / l_{2}^{\prime \prime}=\cdots=C_{l}$.

(2) Kinematic Similarity. Regarding geometric similarity, the model and prototype ensure a corresponding moment of similarity: $t_{1}^{\prime} / t_{1}^{\prime \prime}=t_{2}^{\prime} / t_{2}^{\prime \prime}=\cdots=C_{t}=\sqrt{C_{l}}$.

(3) Stress Similarity. The stress of the materials of the similar model shall be correspondingly similar to the prototype rock: $C_{\sigma}=C_{\gamma} \cdot C_{l}$.

(4) External Force Similarity. This refers to the similarity between the loaded value and stress exerted on the prototype roof: $C_{F}=C_{\gamma} \cdot C_{l}^{3}$.

(5) Dynamic Similarity. For dynamic similarity system, each system shall satisfy Newton's second law: $F=m(d v / d t)$.

Thereby, the following can be inferred: $m_{1}^{\prime} / m_{1}^{\prime \prime}=m_{2}^{\prime} /$ $m_{2}^{\prime \prime}=\cdots=C_{m}=C_{\gamma} C_{l}^{3}$.

(6) Similarity of Initial and Boundary Conditions. Similar to the field condition, for the initial condition, the model test is under the effect of gravity field, along with the application of equivalent surface force to the model. This can be regarded as similar. However, at the boundaries of the model's two sides, the shrinkage cracks make it difficult to ensure similarity with field conditions. This effect can be corrected by correcting the monitored data. In contrast, to the overburden of the failure law far from the boundary, the effect can be ignored. 
TABLE 1: Similarity model parameter design.

\begin{tabular}{lccccccccc}
\hline Parameter & $C_{l}$ & $C_{t}$ & $C_{\gamma}$ & $C_{\sigma}$ & $\begin{array}{c}\text { Model width } \\
(\mathrm{mm})\end{array}$ & $\begin{array}{c}\text { Model height } \\
(\mathrm{mm})\end{array}$ & $\begin{array}{c}\text { Model thickness } \\
(\mathrm{mm})\end{array}$ & $\begin{array}{c}\text { Model roadway } \\
\text { height }(\mathrm{mm})\end{array}$ & $\begin{array}{c}\text { Model roadway } \\
\text { width }(\mathrm{mm})\end{array}$ \\
\hline Value & $1 / 50$ & $1 / \sqrt{50}$ & 0.6 & $1 / 83$ & 1380 & 1290 & 12 & 72 & 80 \\
\hline
\end{tabular}

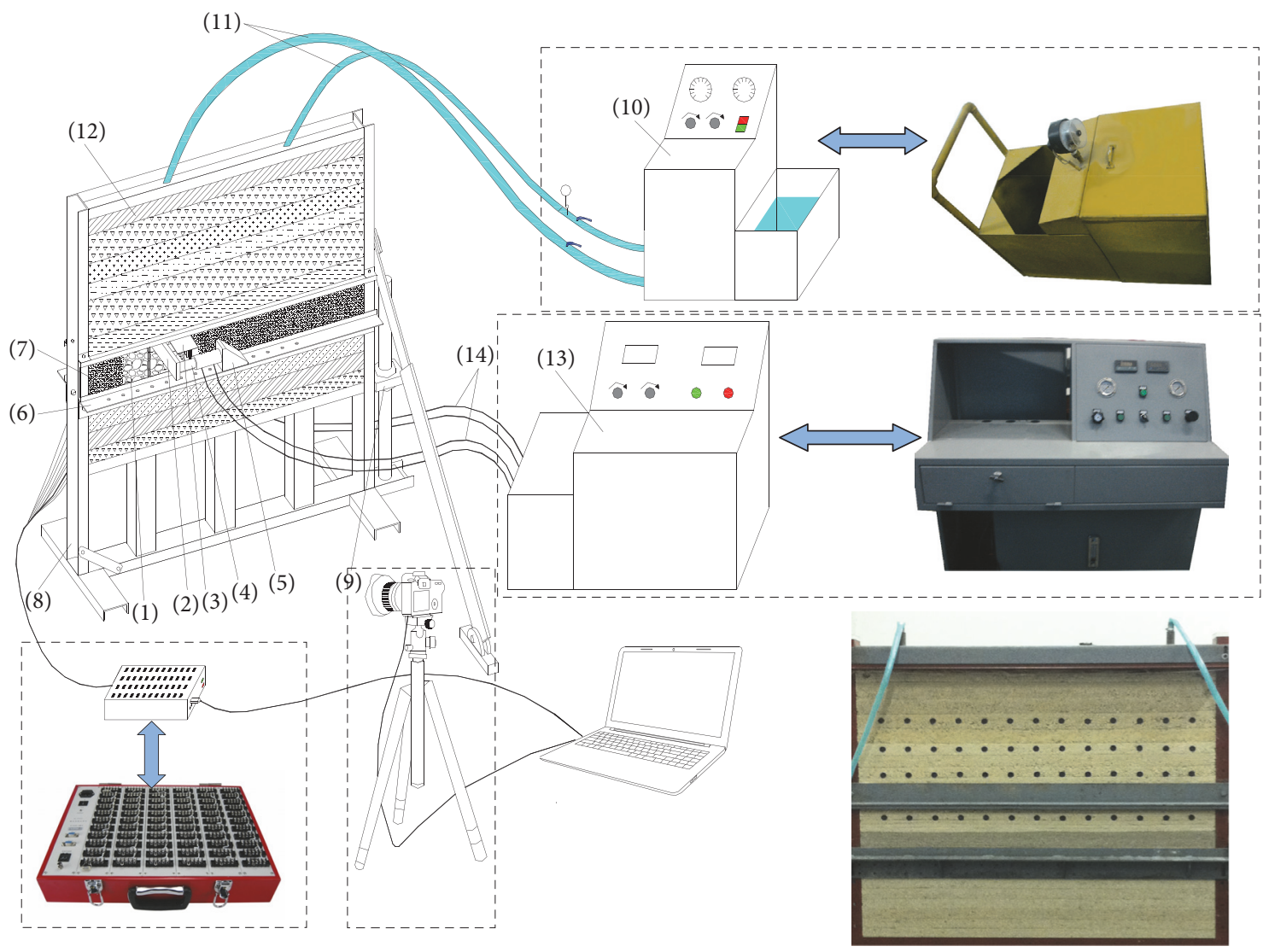

(1) Backfilled granular gangues

(8) Similar material simulation test bench

(2) Pushing device

(9) Angle-adjusting device

(3) Simulation hydraulic support

(10) Water pressure loading console

(4) Hydrocylinder

(11) Water pipe

(5) Base

(12) Water bag baffle

(6) Spout

(7) Gangue baffle

(13) Hydraulic system console

(14) Oil pipe

FIGURE 4: Backfilling GER similar model test system.

In the previous equation, $C_{l}$ is geometric ratio, $C_{t}$ is time ratio, $C_{\gamma}$ is volume-weight ratio, $C_{\sigma}$ is stress ratio, $C_{F}$ is concentrated force similarity ratio, and $C_{m}$ is mass similarity ratio.

To not only ensure adequate BFA space but also simulate all key strata, the geometric ratio $C_{l}$ is selected as 1:50. Table 1 lists the specific similarity model parameters.

Bore-coring is conducted in the coal mine in the test zone, and, through laboratory tests, mechanical property indexes of the coal and rocks in the scope of the mining area are obtained. The strengths of the strata in the model are then obtained based on theoretical calculations of similarity. In this study, sands were selected as the aggregate and lime and gypsum as the cementing materials to prepare similar materials, according to the strength of similar materials ratio in literature $[29,30]$. Next, verification tests were conducted in the laboratory to finally determine the similar materials ratio of various types of rock. Table 2 lists the specific ratios.

2.3.3. Simulation of Granular Materials. The microstructure of the backfill body shows that its internal structure has many pores. Under confining pressure, the pores are closed to make the backfill body compact. As the confining pressure increases, the degree of compaction of the backfill body increases. As granular media, the bonding force between the 


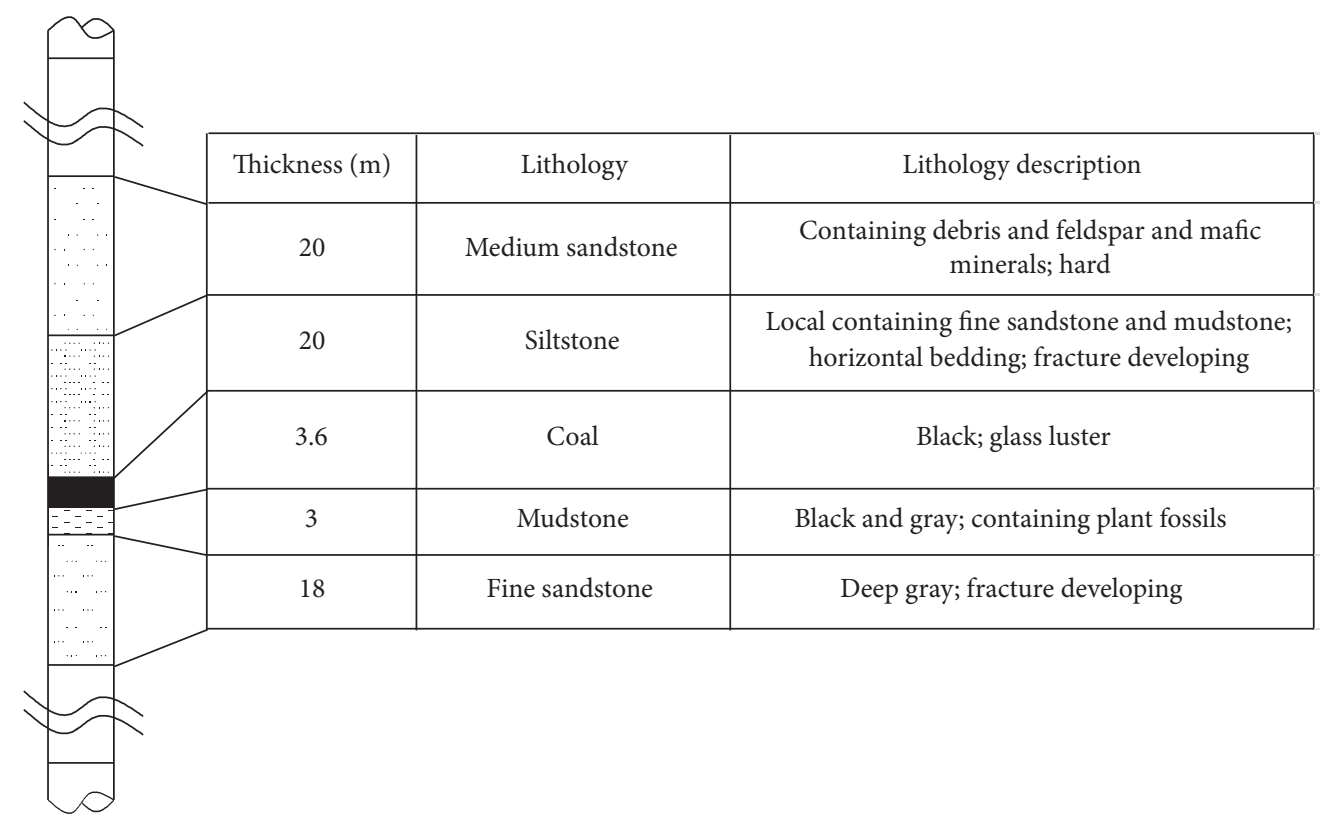

FIGURE 5: Strata geological log.

TABLE 2: Similar material ratios.

\begin{tabular}{|c|c|c|c|c|c|c|c|c|}
\hline \multirow{2}{*}{$\begin{array}{l}\text { Relative } \\
\text { position of rock }\end{array}$} & \multirow[t]{2}{*}{ Rock type } & \multicolumn{2}{|c|}{$\begin{array}{c}\text { Compressive strength } \\
(\mathrm{MPa})\end{array}$} & \multicolumn{3}{|c|}{ Dry material composition (\%) } & \multirow{2}{*}{$\begin{array}{c}\text { Water } \\
\text { content }(\%)\end{array}$} & \multirow[t]{2}{*}{ Sawdust (\%) } \\
\hline & & Prototype & Model & Sand & Lime & Plaster & & \\
\hline \multirow[t]{2}{*}{ Roof } & $\begin{array}{l}\text { Medium } \\
\text { sandstone }\end{array}$ & 120 & 1.44 & 30 & 9 & 61 & 14.3 & l \\
\hline & Siltstone & 90 & 1.08 & 30 & 35 & 35 & 14.3 & l \\
\hline Coal seam & Coal & 20 & 0.36 & 40 & 42 & 18 & 11.1 & 2 \\
\hline \multirow{2}{*}{ Floor } & Mudstone & 45 & 0.54 & 70 & 9 & 21 & 11.1 & l \\
\hline & Fine sandstone & 85 & 1.02 & 30 & 35 & 35 & 14.3 & / \\
\hline $\mathrm{RBB}$ & Gangue concrete & 8 & 0.096 & 80 & 10 & 10 & 11.1 & l \\
\hline
\end{tabular}

solid particles of the backfill body is far less than the strength of the solid particles. Therefore, under limited external loads, compaction primarily results in rearrangement of particles instead of destruction of the solid particles.

Therefore, when conducting simulation of granular materials, the particle size and distribution majorly affecting the compaction characteristics of the backfill body were considered first. The gangues in the BFA are obtained from the accumulated gangue piles in the coal mine of the test zone (Figure 6). In the prototype, the particle size after crushing is required to be less than $100 \mathrm{~mm}$; therefore, in the model, the size of granular particles was less than $2 \mathrm{~mm}$. To express the continuous grading characteristics of the particles in the BFA, this paper introduces the Talbol series:

$$
P_{x}=100\left[\frac{d}{D}\right]^{n}(\%) \text {, }
$$

where $P_{x}$ is the pass percentage of aggregate $d, D$ is the maximum size of the granular gangues, $d$ is the current size of the granular gangue, and $n$ is the Talbol formula coefficient. As shown in Figure 7, the content of different size particles in the prototype is consistent with the distribution characteristics of Talbol coefficient $n=0.6$. The particle sizes of the backfilling material used in the model are scaled down geometrically, and the distribution characteristics are as shown in Figure 6.

2.3.4. Test Scheme and Process. An orthogonal test method was used to establish four similarity test models. Three models have horizontal pushing loads in the prototype of 0 , 1 , and $2 \mathrm{MPa}$ with an RBB with a flexible cushion, and one model has horizontal pushing load of $2 \mathrm{MPa}$ with an $\mathrm{RBB}$ without a flexible cushion (Figure 7). First, the effect of the horizontal pushing load on the BFA stress distribution was analyzed, along with overlying strata subsidence and roadway converging deformation under the same RBB parameter conditions. Second, the effect of the flexible cushion to the RBB stability under the same horizontal pushing load conditions was analyzed. 


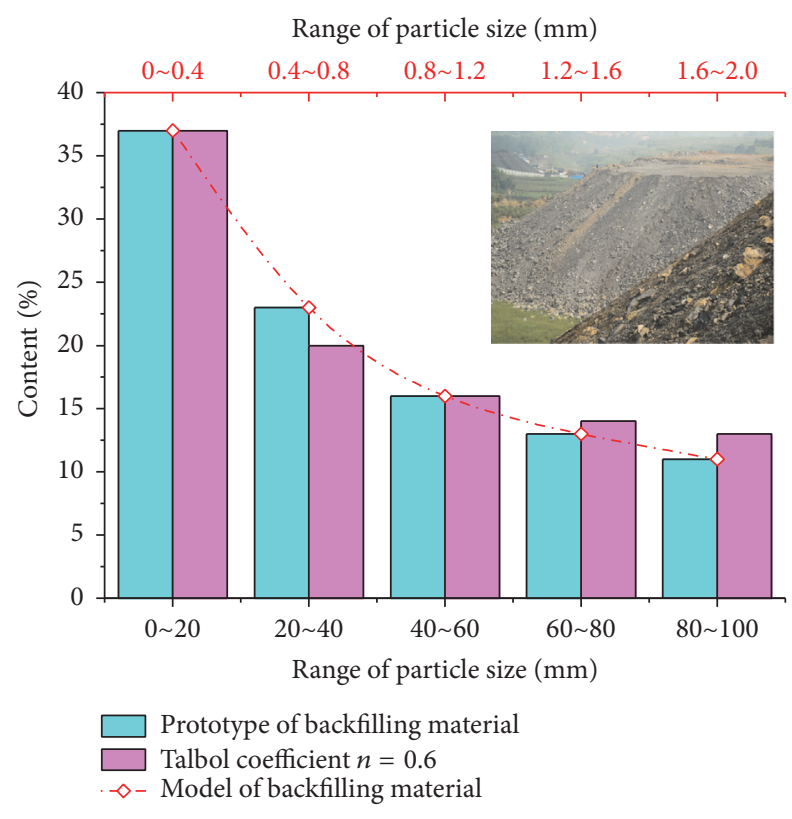

FIGURE 6: Particle size distribution characteristics of backfilling granular material.

As shown in Figure 8, one work cycle on the gangue backfill working face goes through three steps: coal cutting, hydraulic support moving and backfilling, and pushing. During the excavation process in the similar test model, the aforementioned steps were simulated. In the whole GER process, the excavation and filling of the coal seam at the left side of the roadway in the model were conducted in 12 work cycles; each work cycle advances $50 \mathrm{~mm}$, dividing into four operating steps: coal cutting, backfilling, pushing, and stabilization. After each step is completed, the model data was measured. Therefore, the relationship between the measurement times $n$ and the number of work cycles $N$ is as follows:

No. $N$ work cycle "Coal cutting": $n=4 N-3(N=$ $1,2,3, \ldots, 12$ )

No. $N$ work cycle "Backfilling": $n=4 N-2(N=$ $1,2,3, \ldots, 12)$

No. $N$ work cycle "Pushing": $n=4 N-1(N=$ $1,2,3, \ldots, 12)$

No. $N$ work cycle "Stabilization": $n=4 N(N=$ $1,2,3, \ldots, 12)$

\section{Surrounding Rock Deformation Mechanism of GER with Fully Mechanized Gangue Backfilling Mining}

3.1. Granular Bearing Characteristics in the BFA. The model of horizontal pushing load of $2 \mathrm{MPa}$ was used to research the general characteristics of granular material bearing during the excavation process. To eliminate the effect of boundary on the results of the similar materials simulation test, monitoring point " $\mathrm{A}$ " was selected at $200 \mathrm{~mm}$ to the left boundary of the model as the research object, and the stress distribution characteristics and roof deformation law of the fixed monitoring point were analyzed during the model's excavation process (Figure 9).

(1) The stress change at monitoring point A under the effect of the whole mining process can be divided into the following five stages. Stage I is the original rock stress stage (the distance to the lead working face in the prototype is over $10 \mathrm{~m}$ ). As the stage is far away from the working face, the effect of the mining on the working face is very small. Stage II is the advanced stress stage (distance from the lead working face is less than $10 \mathrm{~m}$ in the prototype); as the distance from the working face decreases, the effect of the advanced support pressure of the working face continuously increases, and the vertical stress increases. Stage III is the active compaction stage (within $10 \mathrm{~m}$ from the lagged working face in the prototype); excavation is performed on the working face to monitoring point $\mathrm{A}$, and the pushing device of the hydraulic support is used to exert horizontal pushing load to the granular materials behind the working face. The stress in the BFA increases rapidly. At this stage, the effect of the horizontal pushing load on the stress increase in the BFA is very high. Stage IV is the passive compaction stage; as monitoring point A moves farther away from the backfilling working face, the effect on point A by the horizontal pushing load decreases. The vertical stress increase is primarily due to the passive support of the BFA caused by the roof subsidence; the stress increase is slow. Stage V is the BFA stress stabilization stage (distance from the lagged working face in the prototype is over $15 \mathrm{~m}$ ); as the roof subsidence stabilizes, the compaction degree and vertical stress in the BFA remain unchanged.

(2) Owing to the flowability of the granular backfilling materials, the stress distribution in the BFA is uneven. Based on the bearing characteristics, the BFA can be divided into loose and compacted areas. The stress of the granular material in the loose area is basically at stages III and IV. Moreover, the stress in the compacted area is basically at stage IV. The process of vertical stress increase in the whole BFA satisfies the following relationship:

$$
\sigma=\frac{1}{\left(a+b n^{c}\right)}, \quad(n=20,24,28, \ldots) .
$$

When the horizontal pushing load is $2 \mathrm{MPa}$, the coefficients are as follows: $a=-13, b=-7.2$, and $c=3.8$.

The distance from point A to the backfilling working face $x$ is taken as the independent variable; thus, the above formula can be rewritten as follows:

$$
\sigma(x)=\frac{1}{\left(a^{\prime}-b^{\prime} x^{c^{\prime}}\right)},
$$

where, $a^{\prime}=-18.3, b^{\prime}=-3.0 \times 10^{-4}$, and $c^{\prime}=2.2$.

As shown by the roof subsidence curve, the immediate roof subsidence primarily occurs in the loose area, and the roof subsidence in the compacted area is slow. This is primarily because the gangue materials in the loose area have not formed an effective structure to support the roof. As $x$ increases, the BFA is gradually compacted, the support force increases, and the roof subsidence stabilizes. 


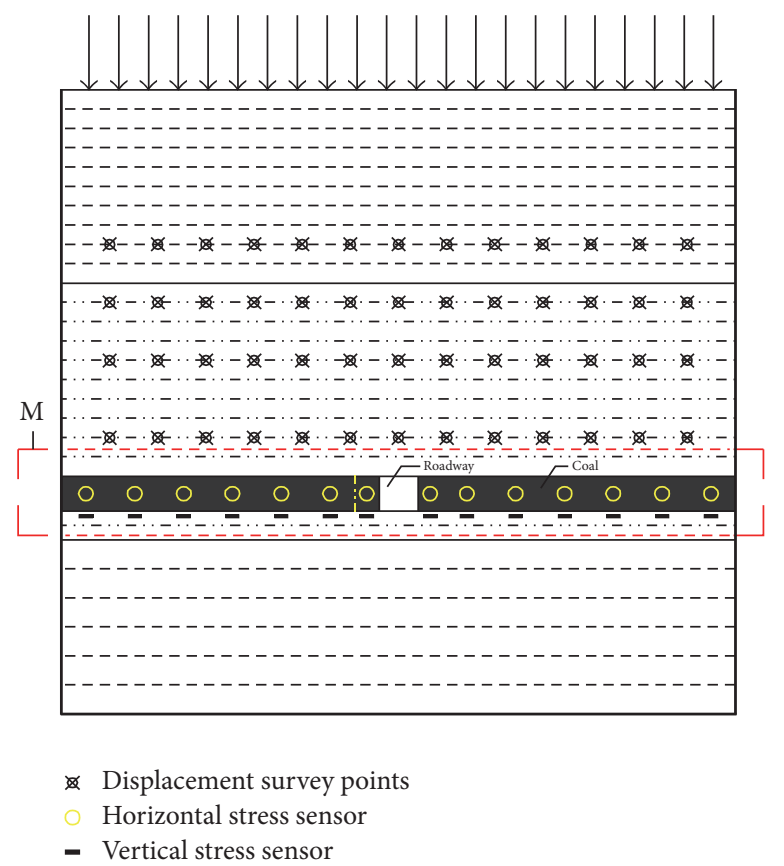

(a) Test model

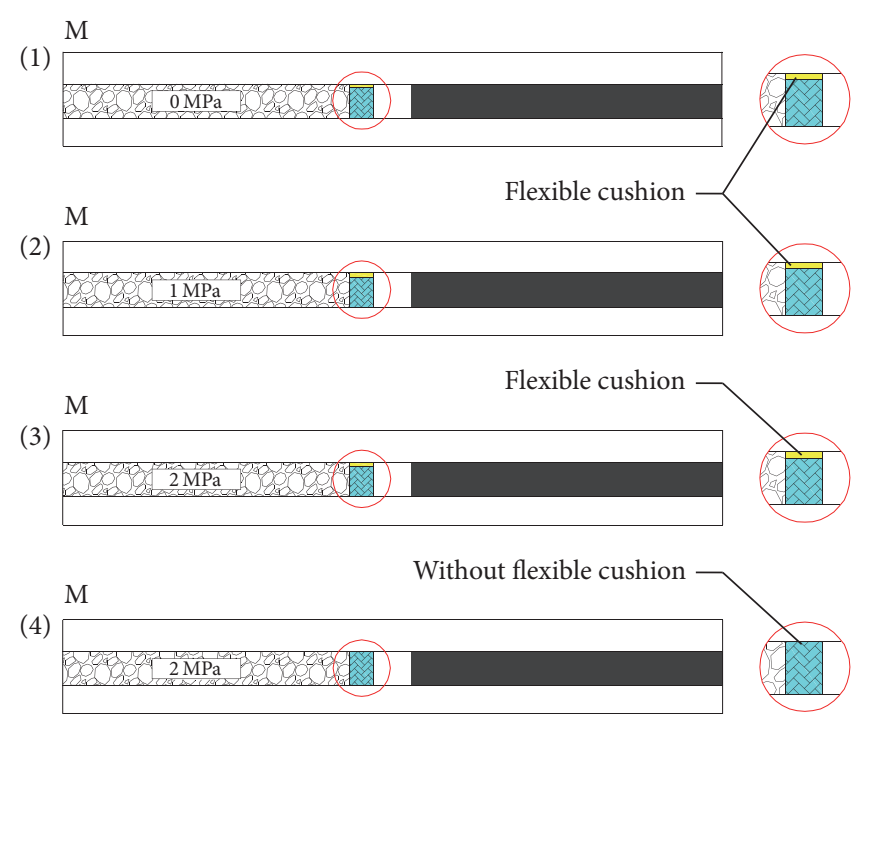

(b) Test scheme

FIGURE 7: Similarity model test scheme design.

(3) In each work cycle at the active compaction stage, the push-press to the backfilling material always causes a certain degree of stress increase in the loose area. After the pushing device is withdrawn, a certain degree of attenuation of the vertical stress always occurs in the loose area. The attenuation rate can be calculated using the following formula:

$$
d(x)=\frac{\sigma_{2}-\sigma_{3}}{\sigma_{2}-\sigma_{1}} \times 100 \%,
$$

where $\sigma_{1}$ is the stress before horizontal pushing, $\sigma_{2}$ is the stress under pushing load, and $\sigma_{3}$ is the stress after the pushing device is withdrawn.

The attenuation rate $d$ of the vertical stress in the loose area gradually decreases as $x$ increases. The attenuation rates at distances of 50,100,150, and $200 \mathrm{~mm}$ from the working face are $58 \%, 52 \%, 35 \%$, and $16 \%$, respectively (Figure 10 ). This indicates that as the compactness and confining pressure in the BFA increase, the effect of efficiency of the horizontal pushing load to the increase of the vertical stress in the BFA also increases. In contrast, within the range of the effect of the active compaction, as the distance from the working face increases, the increase of the stress $\sigma_{2}-\sigma_{1}$ in the BFA caused by the pushing load slows down.

The comparison of the stress evolution processes on the monitoring point at the same position of schemes 1,2 , and 3 (Figure 11) shows that as the horizontal pushing load decreases, the effect range of the advanced support pressure increases, and the stress peak increases. Under the horizontal pushing loads of 2,1 , and $0 \mathrm{MPa}$, the stress concentration factors advanced working face are $1.43,1.57$, and 1.71 , respectively. As the horizontal pushing load decreases, the effective distance on the BFA by the pushing load decreases. In addition, the increase rate of the early stress of the BFA decreases. Therefore, under the combined effect of the previous two factors, the active compaction effect decreases and the range of the loose area increases. Through comparison, it is found that when the horizontal pushing loads are 2 and $1 \mathrm{MPa}$, the lengths of the loose area are 250 and $400 \mathrm{~mm}$, respectively. When there is no horizontal pushing load, the range of the loose area is over $400 \mathrm{~mm}$. Therefore, it can be inferred that the rise of the horizontal pushing load plays an important role in the quick formation of bearing core area in the BFA.

3.2. Analysis of Roof Deformation Law. No fractures occurred on the roof during the course of entry retaining. The uneven subsidence primarily occurred in the transition area between the solid coal and the BFA. A comparison of the subsidence curves of the immediate roof (Figure 12(a)) and the main roof (Figure 12(b)) reveals that the uneven subsidence characteristics of the main roof show a linear increase in subsidence from solid coal to BFA and the change process is milder here than in the immediate roof.

The subsidence rates of the immediate roof at the two sides of the RBB are different, indicating that the support from the RBB can limit the subsidence of the immediate roof and has little effect on the deformation curve of the main roof. The uneven subsidence area in the immediate roof is less than that in the main roof and the subsidence in the immediate roof is larger after stabilization. This is primarily due to inadequate supporting of the granular materials in the BFA at the outer side of the RBB. The immediate roof strata are weaker compared to the main roof. Therefore, 


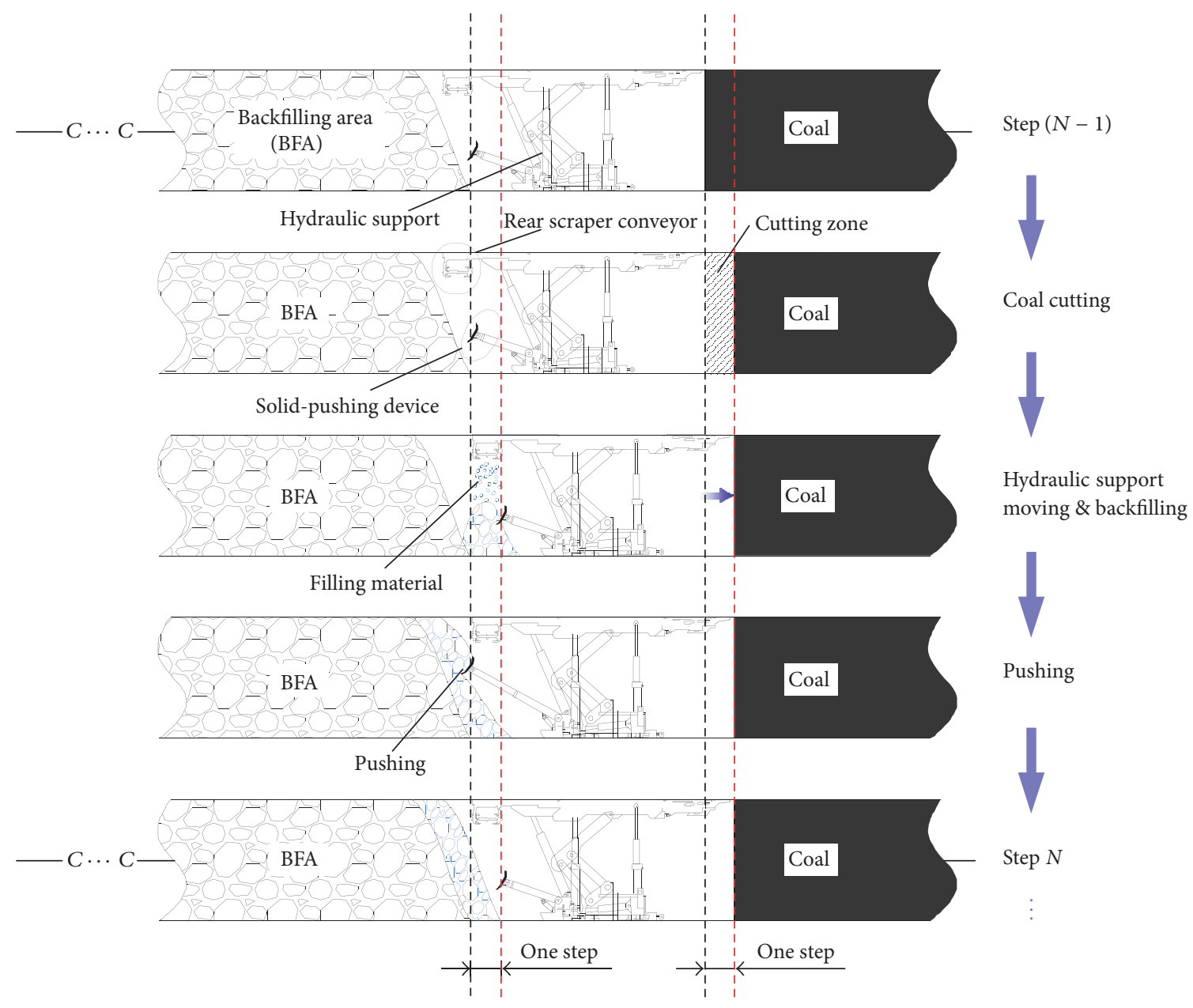

FIGURE 8: Backfilling mining step process.

the deformation is more pronounced under the effects of bending, dislocation, and dilatation.

The subsidence of the main roof is basically a linear change. Therefore, the amount of subsidence after stabilization of the BFA is primarily determined by the bearing characteristics of the granular materials in the BFA. It can be observed by comparing models 1,2 , and 3 in which the maximum amount of subsidence in the immediate roof shows a nonlinear decrease with the increase in the horizontal pushing load during the backfilling process. The compactions of the granular materials are the same under the final stabilized condition when all three models have the same filling height and the same equivalent load at the top. It can be inferred that during the preliminary compaction process of loose backfilling materials under $0-2 \mathrm{MPa}$, the increase rate of compaction gradually decreases.

The main function of the RBB is not to cut off the main roof or limit the deformation of the main roof but to limit the bed separation and subsidence of the immediate roof while adapting to the deformation of the main roof. It can be seen from the comparison between models 3 and 4 that the roadway roof deformation is high in $\mathrm{RBB}$ without a flexible cushion. This is because an RBB without a flexible cushion cannot adapt to the deformation of the main roof. Additionally, the stress concentration factor in the RBB is very high resulting in local failure in the RBB. Consequently, its controlling effect on the immediate roof becomes poor.

Based on the analysis of internal stress in the BFA and the roof deformation, it can be said that no factures occurred in the main roof during the process of solid backfilling of the GER, and the overlying strata load was transferred downwards through the main roof. The BFA functions as the main support to the main roof when the coal is replaced with the gangues. On one hand, the immediate roof adapts to the rotational deformation of the main roof and, on the other hand, a certain degree of bed separation and subsidence will occur in the immediate roof itself. The method of limiting the rotation of the main roof by the supporting effect of the $\mathrm{RBB}$ is unfeasible. A practical RBB needs to adapt to the given deformation of the main roof. Additionally, the RBB needs to fence out the gangues, limit the immediate roof to prevent bed separation, and control the converging deformation of the roadway. Therefore, the $\mathrm{RBB}$ that makes use of the flexible packing layer innovatively designed in this study paves a solid way for surrounding rock control in backfilling of GER using gangue. 


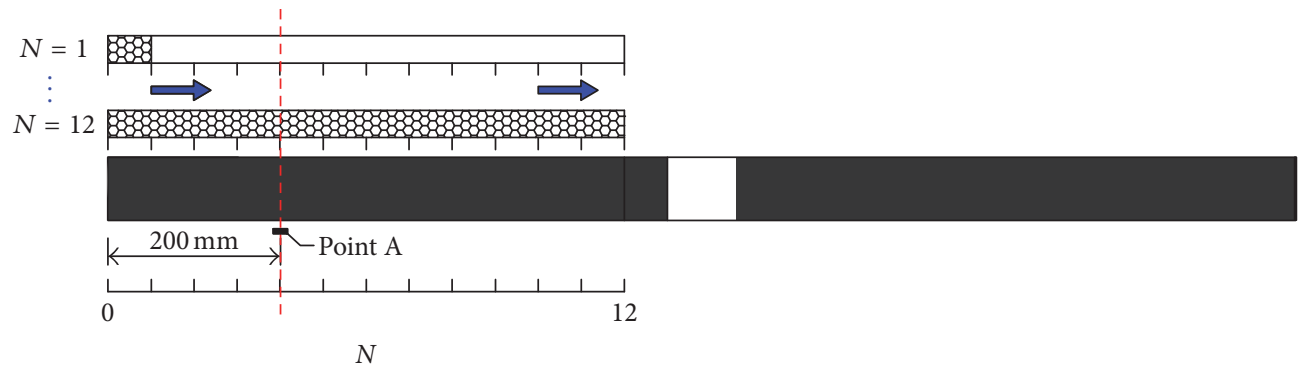

(a) Monitoring points layout and test process

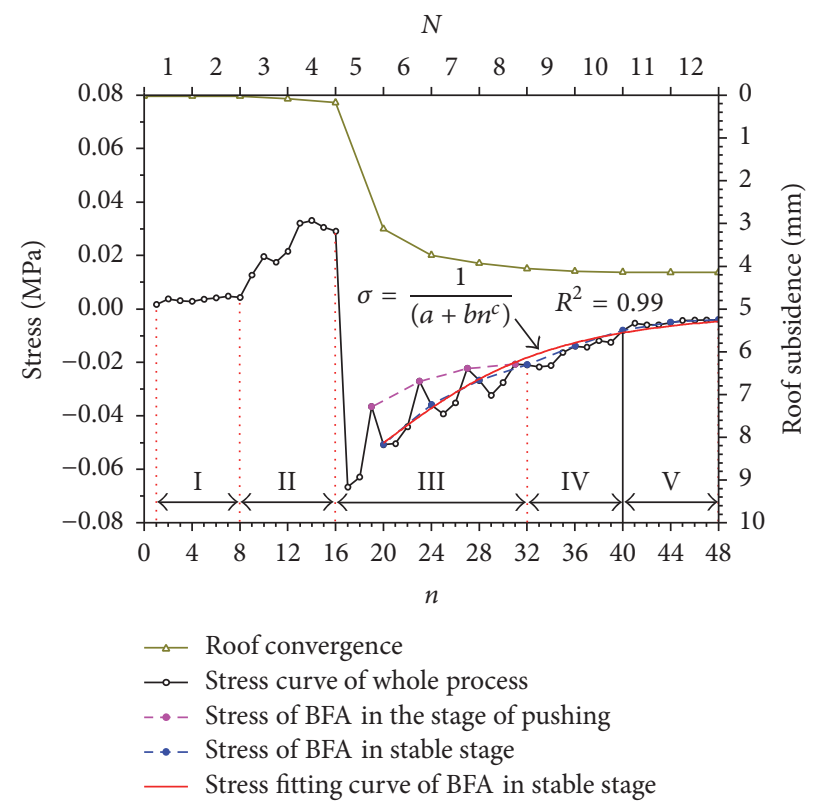

(b) Monitoring results of monitoring points

FIGURE 9: Monitoring point stress and displacement evolution process during model excavation.

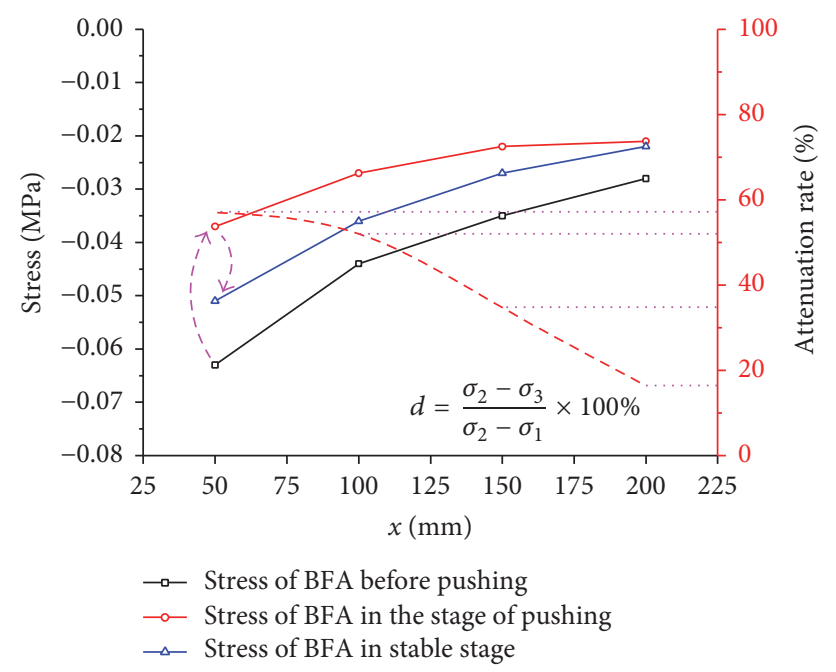

FIgURE 10: Stress evolution process in the loose area during pushing process. 


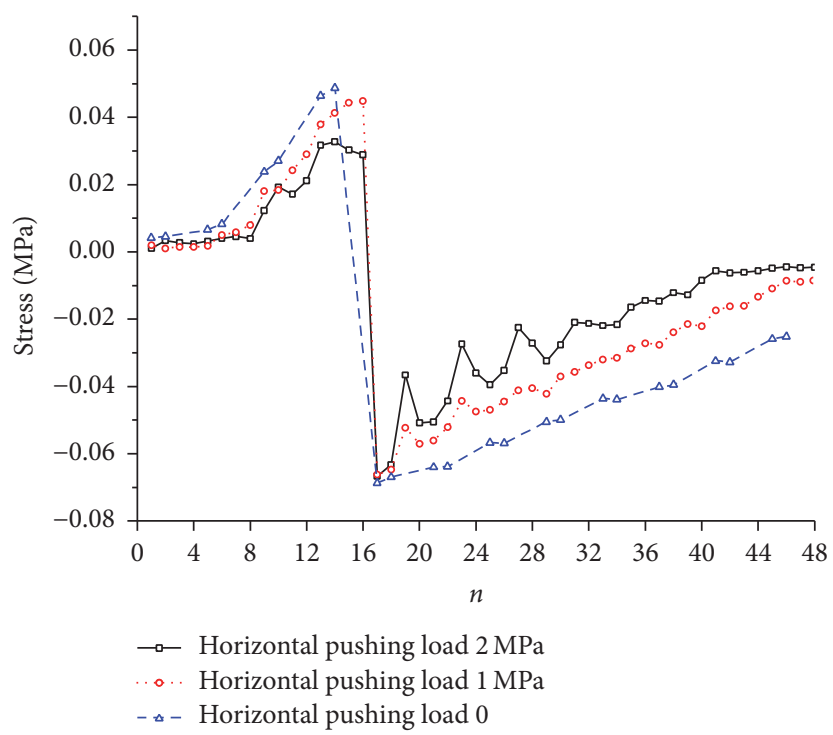

FIGURE 11: Stress evolution process of monitoring points at different horizontal pushing load.
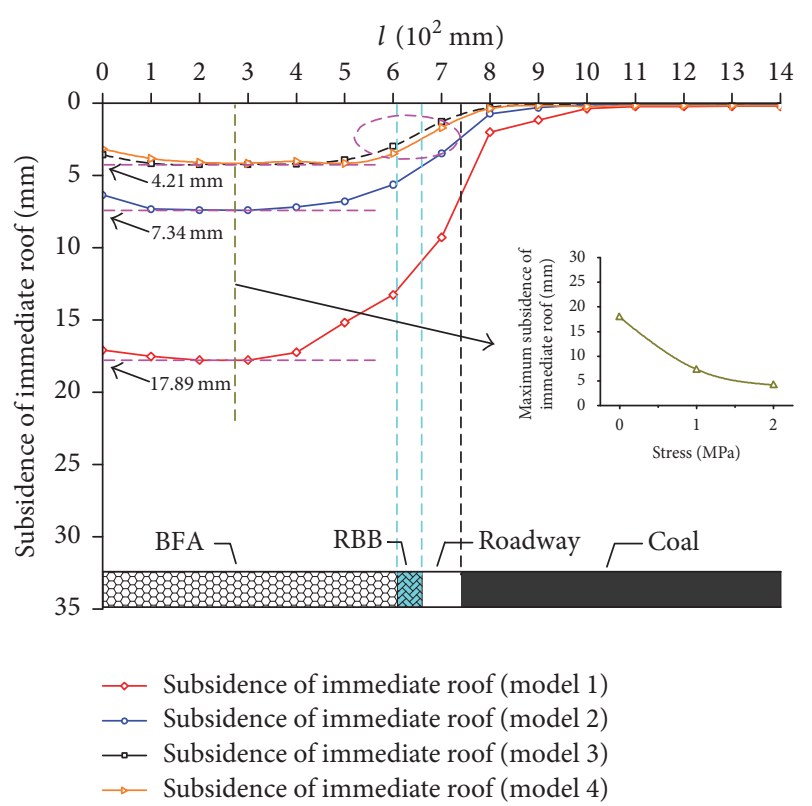

(a) Immediate roof

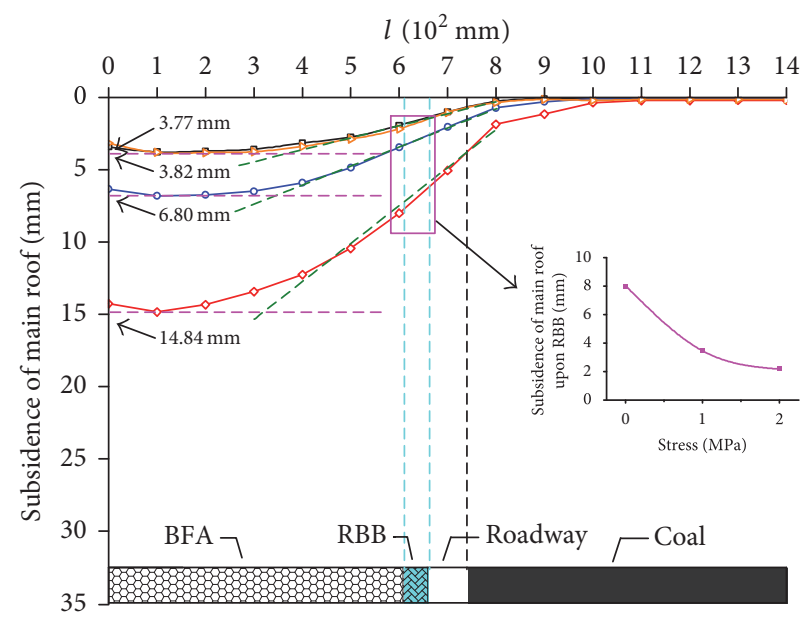

$\because$ Subsidence of main roof (model 1)

$\therefore$ Subsidence of main roof (model 2)

$\rightarrow$ Subsidence of main roof (model 3 )

$\rightarrow$ Subsidence of main roof (model 4)

(b) Main roof

FIgURE 12: Roof subsidence curve.

3.3. RBB Stability Analysis. As can be seen from Figure 13, a flexible packing layer was added to the top of the RBB in model 3 while keeping other conditions the same. After GER was completed, the flexible cushion in the RBB was compressed. The integrity of the lower main supporting body was good and bed separation did not occur in the immediate roof. In model 4, a flexible packing layer was not provided at the top of the RBB. The top was in direct contact with the roof. After GER was completed, failure and instability occurred in the RBB and bed separation occurred in the immediate roof. This proves that adding a flexible packing layer at the top of the RBB can effectively prevent failure due to very high-stress concentration in the RBB. Therefore, in reference to the subsidence curves of the main roof over the RBB under different horizontal pushing loads as shown in Figure 12, the yieldability of the flexible packing layer in the RBB parameter design should be slightly higher than the given deformation of the main roof. The roadway deformation can be effectively controlled by using the flexible packing layer to absorb the main roof deformation while simultaneously using the lower supporting body to support the immediate roof.

The results obtained from the observation of lateral pressure at the even subsidence stage of the BFA indicate that the lateral pressure coefficient of the granular gangues 

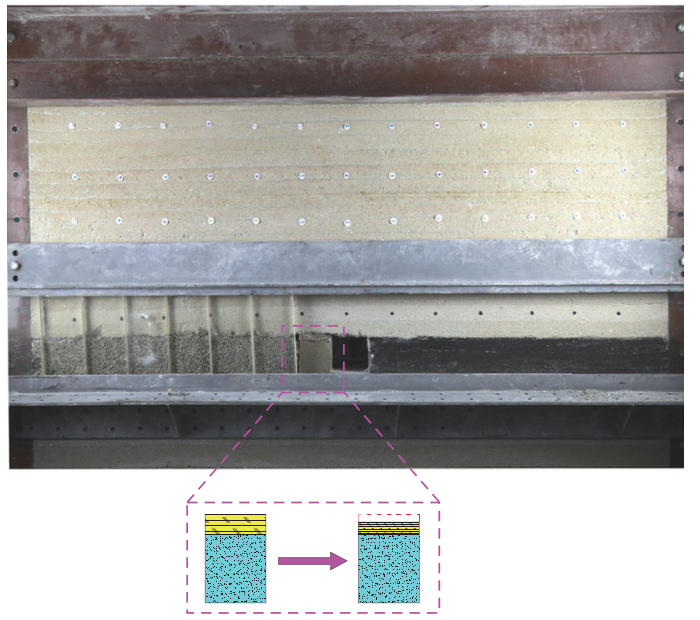

(a) With flexible packing layer (scheme 3)

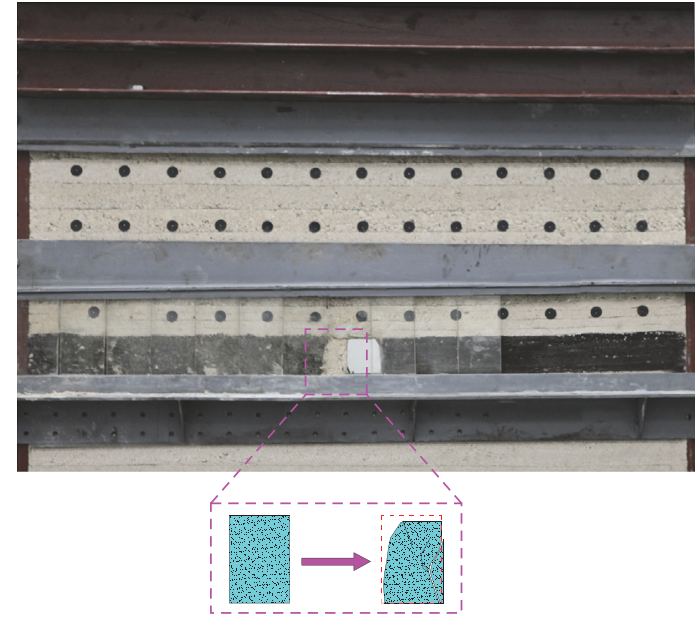

(b) Without flexible packing layer (scheme 4)

FIGURE 13: Support effect of gob-backfilled GER.

is $0.4 \sim 0.43$. The lateral pressure in the loose area at the outer side of the RBB is only $0.11 \sim 0.14$ times the vertical support force of the RBB. Therefore, no lateral instability occurred in the $\mathrm{RBB}$ of aspect ratio 1.8 that was used in the tests during the experimental process.

\section{Field Test and Monitoring}

4.1. Parameter Design Principle. Based on the above analysis results, the following recommendations are proposed for parameters of the gob-backfilled process and GER support design in engineering practice.

(1) With respect to the parameter design for the gangue backfilling working face, the bearing characteristics of the BFA determine the subsidence law of the main roof. Because the subsidence of the main roof can be seen as an irreversible process, the bearing core area formation speed should be increased by increasing the horizontal pushing load of the backfilling hydraulic support. Quick compaction of the BFA can effectively control the main roof subsidence. On the other hand, the attenuation rate $d$ of the pushing load should be reduced by the optimization of gangue grading, addition of modified material, and vibration of the pushing load. The compaction speed of the BFA can be improved by using a constant pushing load.

(2) With respect to the RBB design, the RBB should be able to provide adequate support force to limit the occurrence of bed separation in the immediate roof. Additionally, a flexible shrinkable packing layer that adapts to the main roof subsidence should be placed at the upper part of the RBB. The thickness of the packing layer should be based on the deformation curve of the main roof at the upper part of the $\mathrm{RBB}$ under different horizontal pressure conditions as shown in Figure 12(b). On the other hand, to improve the bearing capacity of the RBB and prevent failures from occurring due to overload as shown in Figure 13(b), opposing prestressed bolts should be arranged in the RBB to restrain lateral deformation.

(3) With respect to entry-in reinforced support, a highresistance-yielding individual hydraulic prop should be adopted for the GER within a certain range behind the working face during backstopping to reinforce roof support. Before the granular materials in the BFA are compacted and stabilized, use the synergistic effects of the support strength of the individual hydraulic prop and the early strength of the RBB to support the roof effectively and reduce the roadway roof deformation. The individual hydraulic prop can be withdrawn after the BFA materials have entered the compacted area.

4.2. Field Test. Based on the above design principles and the geological conditions of the test mine, an industrial test of the fully mechanized gangue backfilling GER technology was conducted. A field test of the relevant technical indexes was also conducted. The parameter design for surrounding rock control using the gangue backfilled GER is as follows.

(1) To ensure the controlling effect of the BFA on the roof deformation and ground subsidence, the ratio at the backfilling working face was designed as $100 \%$ and the horizontal pushing load of the hydraulic support was $2 \mathrm{MPa}$.

(2) The width of the RBB was $2 \mathrm{~m}$ and the height was $3.6 \mathrm{~m}$. The self-prepared high-water material at a water-binder ratio of $3: 1$ was used as the flexible shrinkable support material at a height of $200 \mathrm{~mm}$. Concrete with $50 \%$ of gangue content was used as the lower main bearing material at a height of $3400 \mathrm{~mm}$. Counter-pulled bolts of diameter $22 \mathrm{~mm}$ and length 


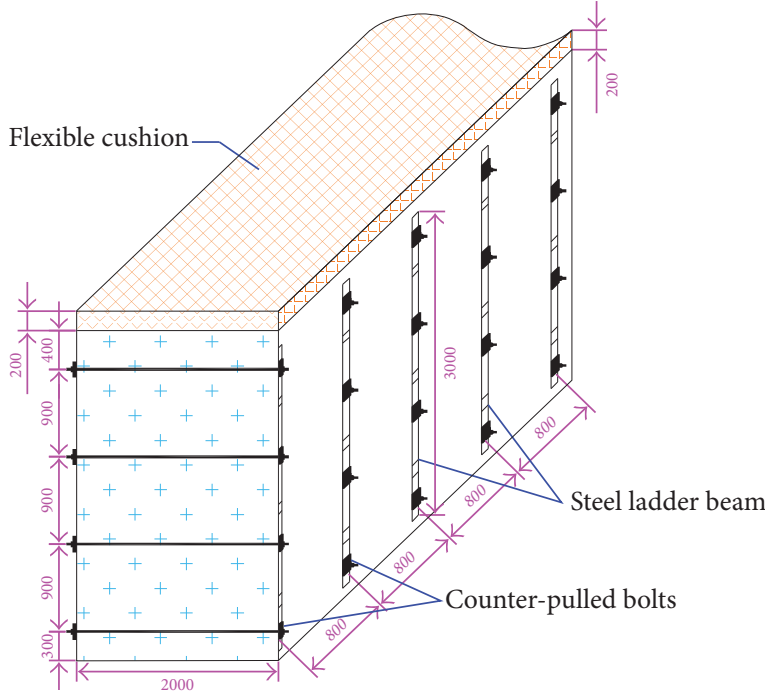

(a) Roadside support design

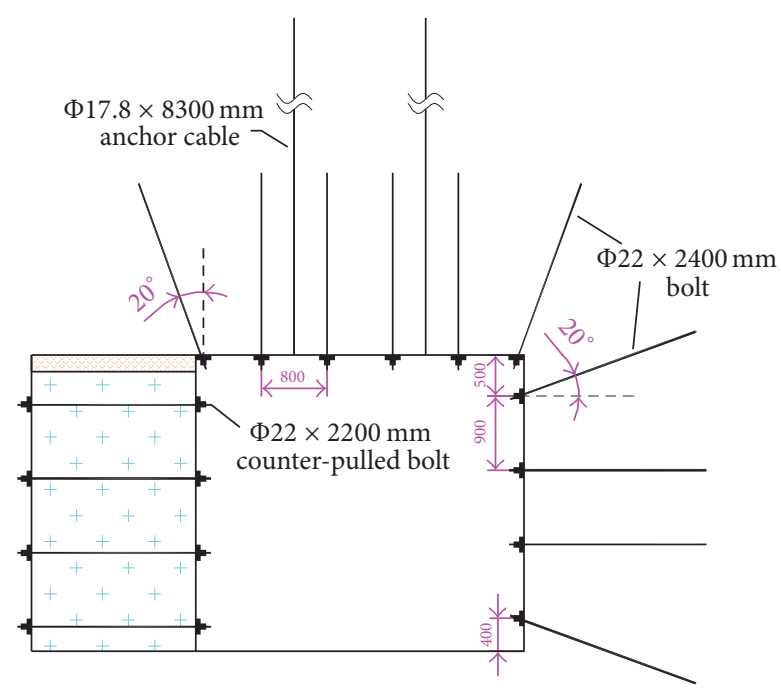

(b) Roadway support design

FIgURE 14: Roadway support design scheme.

$2200 \mathrm{~mm}$ were placed in the RBB and an anchor mesh was provided on the surface of the RBB. The array pitch of the bolts along the length of the roadway was $800 \mathrm{~mm}$. The spacing along the height of the RBB was $900 \mathrm{~mm}$. A steel ladder beam of length $3000 \mathrm{~mm}$ was placed along the height of the RBB between the bolts as shown in Figure 14.

(3) The diameters of the bolts used for entry-in support were $22 \mathrm{~mm}$ and their lengths were $2400 \mathrm{~mm}$. The diameter of the anchor cable was $17.8 \mathrm{~mm}$ and its length was $8300 \mathrm{~mm}$. In the same support section, the spacing between the bolts on the roof was $800 \mathrm{~mm}$ and the spacing between the anchor cables was $1600 \mathrm{~mm}$. The spacing between bolts at the solid coal area was $900 \mathrm{~mm}$ and the vertex angle bolts deflected $20^{\circ}$ toward the outer side of the roadway. The array pitch of the anchors and anchor cables along the length direction of the roadway was $800 \mathrm{~mm}$. To ensure the stability of the GER under the effect of mining and backfilling, individual hydraulic props were arranged from $35 \mathrm{~m}$ in front of the working face to $65 \mathrm{~m}$ behind the working face at intervals of $1 \mathrm{~m}$.

4.3. Field Monitoring. To analyze the effect of GER with fully mechanized gangue backfill mining, monitoring stations were arranged on the roadway to record the converging deformation during advancement of the working face as shown in Figure 15. During advancement of the working face, the roof-floor displacement of the roadway was larger than the two-side displacement. The maximum roof-floor displacement was $112 \mathrm{~mm}$ and the maximum two-side displacement was $71 \mathrm{~mm}$. The roadway deformation speed was the highest within the range of $0-27 \mathrm{~m}$ behind the coal wall of the working face (i.e., $0-20 \mathrm{~m}$ behind the free backfilling face). When the coal wall of the working face exceeded the monitoring station by $27 \mathrm{~m}$, the roof-floor displacement reached $90 \mathrm{~mm}$, which accounted for $80.4 \%$ of the late period steady deformation. At this time, the two-side displacement reached $56 \mathrm{~mm}$, which accounted for $78.9 \%$ of the late period steady deformation. This indicates that the BFA can quickly enter compaction stable stage after the stress adjustment in the loose area and the retained entry deformation has stabilized. The roadway section after stabilized deformation satisfies the design and application requirements (Figure 15). The gangue backfilled GER has the characteristics of fast stabilization, less roadway deformation, no fracture of main roof strata, nonpronounced strata pressure behavior, and less ground subsidence when compared to the GER technology in a roof managed by the caving method. The field test results show that the parameter design principles obtained from the simulation test using similar materials was successfully applied in the field working process.

\section{Conclusion}

Problems relating to high roof pressure, difficulty in roadside support, and serious roadway deformation are obvious in the existing GER technology for roof management using the caving method under multiple complex conditions of high stress, large mining height, and soft-weak roof. These result in low entry-retention success rate, which significantly restrains the promotion and development of the GER technology. Therefore, an innovative GER method with fully mechanized gangue backfill mining was proposed in this study, which has the characteristics of being safe, efficient, and environmentally friendly.

A simulation experiment using similar materials was conducted to simulate the entire backfilled GER process. The simulation test system contained an independently developed horizontal pushing load device. Research on the effects of 


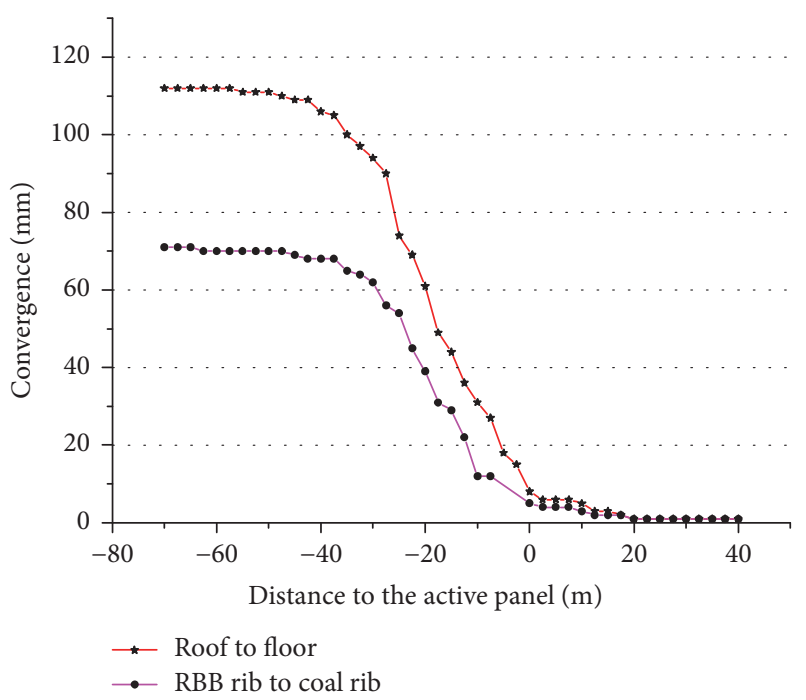

(a) Roadway deformation curve

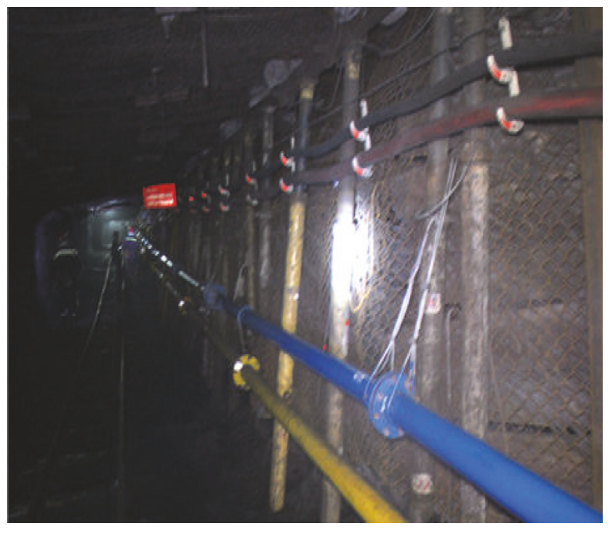

(b) Field entry-retention result

FIGURE 15: Result monitoring of GER with fully mechanized gangue backfilling mining.

different horizontal pushing loads on the increase in stress in the BFA, the loose area range, and the roof subsidence was conducted for the first time. The test results show that the BFA plays a major role in supporting the upper roof. The compaction speed of the BFA can be improved and the main roof subsidence can be reduced by increasing the horizontal pushing load and reducing the attenuation rate of the horizontal pushing load. On one hand, the immediate roof adapts to the rotational deformation of the main roof. On the other hand, a certain degree of bed separation and subsidence occurs.

A new RBB structure with a flexible packing layer was proposed. It was found through test comparison that the method of limiting the main roof rotation using the supporting effect of the RBB was not feasible. RBB with a flexible packing layer could adapt to the given deformation of the main roof while providing adequate supporting force to control the subsidence of the immediate roof.

Field test and monitoring results showed that using a $2 \mathrm{MPa}$ horizontal pushing load can allow the BFA to enter the compaction and stabilization stages quickly. A flexible, 200mm-high-water packing layer arranged at the upper part of the $\mathrm{RBB}$ can adapt to the given deformation of the main roof. The roadway section after the stabilized deformation satisfies the design and application requirements. The feasibility and rationality of the GER technology with fully mechanized gangue backfill mining were proved, which provides a reference basis for the applications of the GER technology under multiple complex geological conditions.

\section{Conflicts of Interest}

The authors declare that there are no conflicts of interest regarding the publication of this paper.

\section{Acknowledgments}

This work is supported by the National Natural Science Foundation of China (nos. 51323004, 51674250, and 51074163); Major Program of National Natural Science Foundation of China (no. 50834005); the Graduate Innovation Fund Project of Jiangsu Province (no. CXZZ13_0924); and Open Fund of State Key Laboratory for Geomechanics and Deep Underground Engineering (SKLGDUEK1409). The authors sincerely acknowledge the former researchers for their excellent works, which greatly helped their academic study.

\section{References}

[1] H. Yang, S. Cao, S. Wang, Y. Fan, S. Wang, and X. Chen, "Adaptation assessment of gob-side entry retaining based on geological factors," Engineering Geology, vol. 209, pp. 143-151, 2016.

[2] J.-H. Xue and C.-L. Han, "Strata behavior and control countermeasures for the gob-side entry retaining in the condition of large mining height," Journal of Mining \& Safety Engineering, vol. 29, no. 4, pp. 466-473, 2012.

[3] X. He and L. Song, "Status and future tasks of coal mining safety in China," Safety Science, vol. 50, no. 4, pp. 894-898, 2012.

[4] G. Vižintin, M. Kocjančič, and M. Vulić, "Study of coal burst source locations in the velenje colliery," Energies, vol. 9, no. 7, p. $507,2016$.

[5] Y. Qin, W. Liu, C. Yang, Z. Fan, L. Wang, and G. Jia, "Experimental study on oxygen consumption rate of residual coal in goaf," Safety Science, vol. 50, no. 4, pp. 787-791, 2012.

[6] J. Ning, P. Ma, X. Liu, J. Zhao, and W. Liu, "Supporting mechanism of 'yielding-supporting' beside roadway maintained along the goaf under hard rocks," Journal of Mining \& Safety Engineering, vol. 30, no. 3, pp. 369-374, 2013.

[7] D. Zhang, X. Miao, and X. Mao, "Simulation on roof activities of gob-side entry retaining in fully-mechanized top-coal caving 
faces," Journal of China University of Mining \& Technology, vol. 30, no. 3, pp. 47-50, 2001.

[8] Y. Lu, S. Zuo, Z. Ge, S. Xiao, and Y. Cheng, "Experimental study of crack initiation and extension induced by hydraulic fracturing in a tree-type borehole array," Energies, vol. 9, no. 7, article 514, 2016.

[9] Y. Lu, Y. Cheng, Z. Ge, L. Cheng, S. Zuo, and J. Zhong, "Determination of fracture initiation locations during cross-measure drilling for hydraulic fracturing of coal seams," Energies, vol. 9, no. 5, article 358, 2016.

[10] Z. Zhang, J. Bai, Y. Chen, and S. Yan, "An innovative approach for gob-side entry retaining in highly gassy fullymechanized longwall top-coal caving," International Journal of Rock Mechanics and Mining Sciences, vol. 80, pp. 1-11, 2015.

[11] J. Bai, H. Zhou, C. Hou, X. Tu, and D. Yue, "Development of support technology beside roadway in goal-side entry retaining for next sublevel," Journal of China University of Mining \& Technology, vol. 33, no. 2, pp. 59-62, 2004.

[12] C.-L. Han, N. Zhang, G.-C. Li, B.-Y. Li, and H. Wu, "Stability analysis of compound bearing structure of gob-side entry retaining with large mining height," Chinese Journal of Geotechnical Engineering, vol. 36, no. 5, pp. 969-976, 2014.

[13] Y. Li and X. Hua, "Mechanical analysis of stability of key blocks of overlying strata for gob-side entry retaining and calculating width of roadside backfill," Rock and Soil Mechanics, vol. 33, no. 4, pp. 1134-1140, 2012.

[14] Y. Chen, J. Bai, X. Wang et al., "Support technology research and application inside roadway of gob-side entry retaining," Journal of the China Coal Society, vol. 37, no. 6, pp. 903-910, 2012.

[15] B. Jiang, L. Wang, Y. Lu, S. Gu, and X. Sun, "Failure mechanism analysis and support design for deep composite soft rock roadway: a case study of the yangcheng coal mine in China," Shock and Vibration, vol. 2015, Article ID 452479, 14 pages, 2015.

[16] X. Sun, X. Liu, G. Liang, D. Wang, and Y. Jiang, "Key parameters of gob-side entry retaining formed by roof cut and pressure releasing in thin coal seams," Chinese Journal of Rock Mechanics and Engineering, vol. 33, no. 7, pp. 1449-1456, 2014.

[17] M. Rezaei, M. F. Hossaini, and A. Majdi, "Determination of longwall mining-induced stress using the strain energy method," Rock Mechanics and Rock Engineering, vol. 48, no. 6, pp. 2421-2433, 2015.

[18] H. Yang, S. Cao, Y. Li, C. Sun, and P. Guo, "Soft roof failure mechanism and supporting method for gob-side entry retaining," Minerals, vol. 5, no. 4, pp. 707-722, 2015.

[19] H. Li, D. Jiang, and D. Li, "Analysis of ground pressure and roof movement in fully-mechanized top coal caving with large mining height in ultra-thick seam," Journal of the China Coal Society, vol. 39, no. 10, pp. 1956-1960, 2014.

[20] S.-R. Xie, G.-C. Zhang, S.-S. He et al., "Surrounding rock control mechanism and its application of gob-side retaining entry in deep backfilling with large mining height," Journal of the China Coal Society, vol. 39, no. 12, pp. 2362-2368, 2014.

[21] X. Feng, N. Zhang, L. Gong, F. Xue, and X. Zheng, "Application of a backfilling method in coal mining to realise an ecologically sensitive 'black gold' industry," Energies, vol. 8, no. 5, pp. 36283639, 2015.

[22] Z. Ma, R. Gu, Z. Huang, G. Peng, L. Zhang, and D. Ma, “Experimental study on creep behavior of saturated disaggregated sandstone," International Journal of Rock Mechanics and Mining Sciences, vol. 66, pp. 76-83, 2014.
[23] Y. Wu, "Effectiveness and development direction of filling mining technology in China's coal mines," China Coal, vol. 38, no. 6, pp. 5-10, 2012.

[24] X. Miao and J. Zhang, "Analysis of strata behavior in the process of coal mining by gangue backfilling," Journal of Mining \& Safety Engineering, vol. 24, no. 4, pp. 379-382, 2007.

[25] H. Li, "Optimum of support parameter of soft-rock roadway and engineer practice," Chinese Journal of Rock Mechanics and Engineering, vol. 19, no. 5, pp. 651-654, 2000.

[26] S. Jeon, J. Kim, Y. Seo, and C. Hong, "Effect of a fault and weak plane on the stability of a tunnel in rock-a scaled model test and numerical analysis," International Journal of Rock Mechanics \& Mining Sciences, vol. 41, no. 1, pp. 658-663, 2004.

[27] D. N. Chapman, S. K. Ahn, D. V. L. Hunt, and A. H. C. Chan, "The use of model tests to investigate the ground displacement associated with multiple tunnel construction in soil," Tunnelling \& Underground Space Technology, vol. 21, no. 3, p. 413, 2006.

[28] F. Huang, H. Zhu, Q. Xu, Y. Cai, and X. Zhuang, "The effect of weak interlayer on the failure pattern of rock mass around tunnel-scaled model tests and numerical analysis," Tunnelling \& Underground Space Technology, vol. 35, pp. 207-218, 2013.

[29] J. Dong, J. Yang, G. Yang, F. Wu, and H. Liu, "Research on similar material proportioning test of model test based on orthogonal design," Journal of the China Coal Society, vol. 37, no. 1, pp. 44-49, 2012.

[30] S. Chen, H. Wang, J. Zhang, H. Xing, and H. Wang, "Lowstrength similar materials for backfill mining: insight from experiments on components and influence mechanism," Geotechnical Testing Journal, vol. 38, no. 6, pp. 929-935, 2015. 


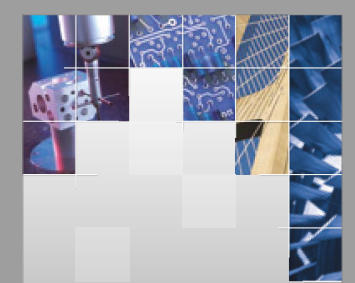

\section{Enfincering}
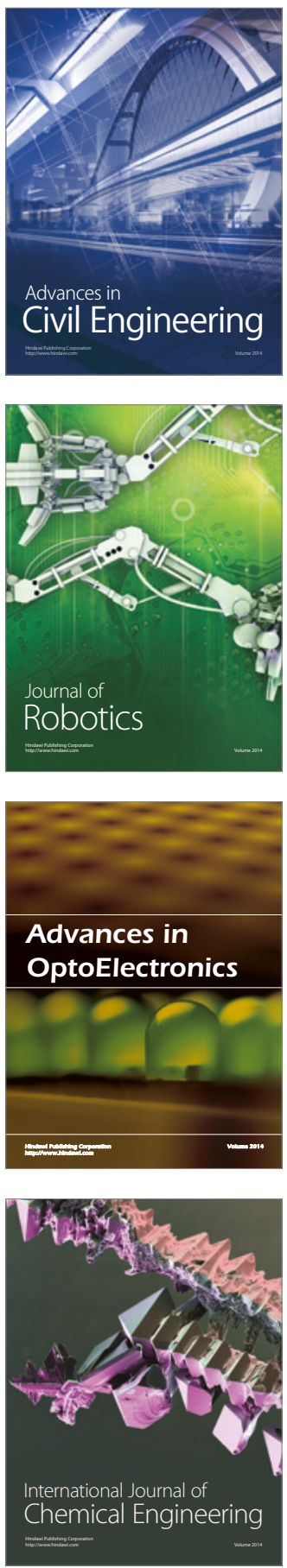

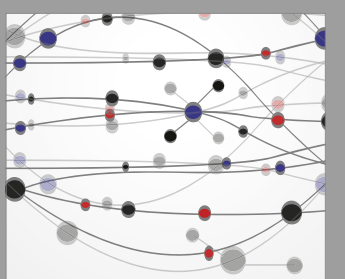

The Scientific World Journal

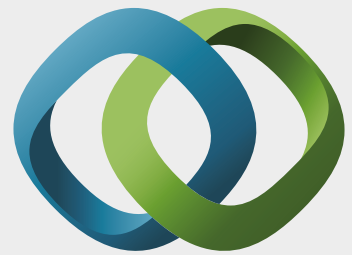

\section{Hindawi}

Submit your manuscripts at

https://www.hindawi.com
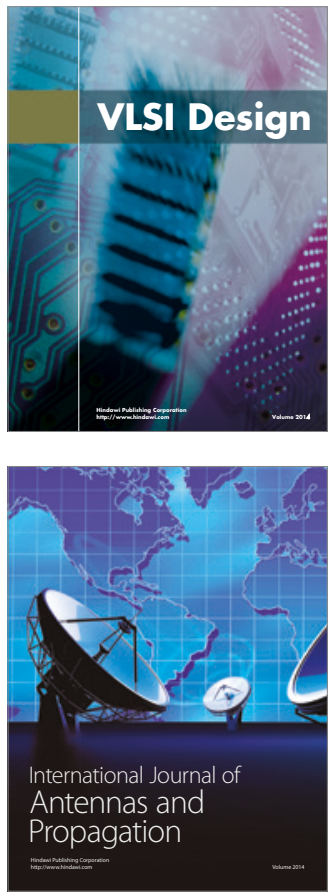

\section{Rotating}

Machinery
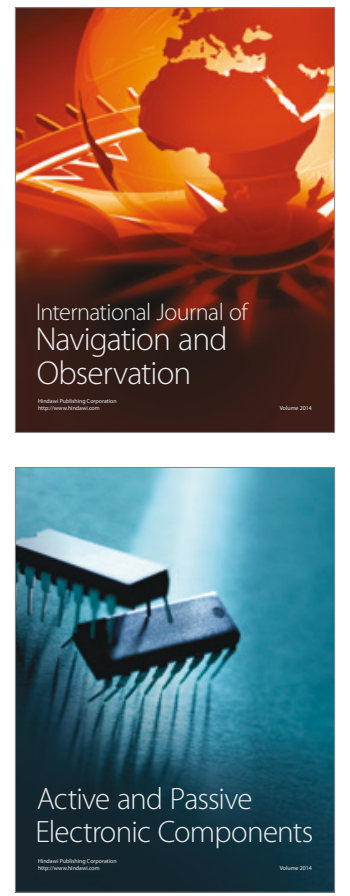
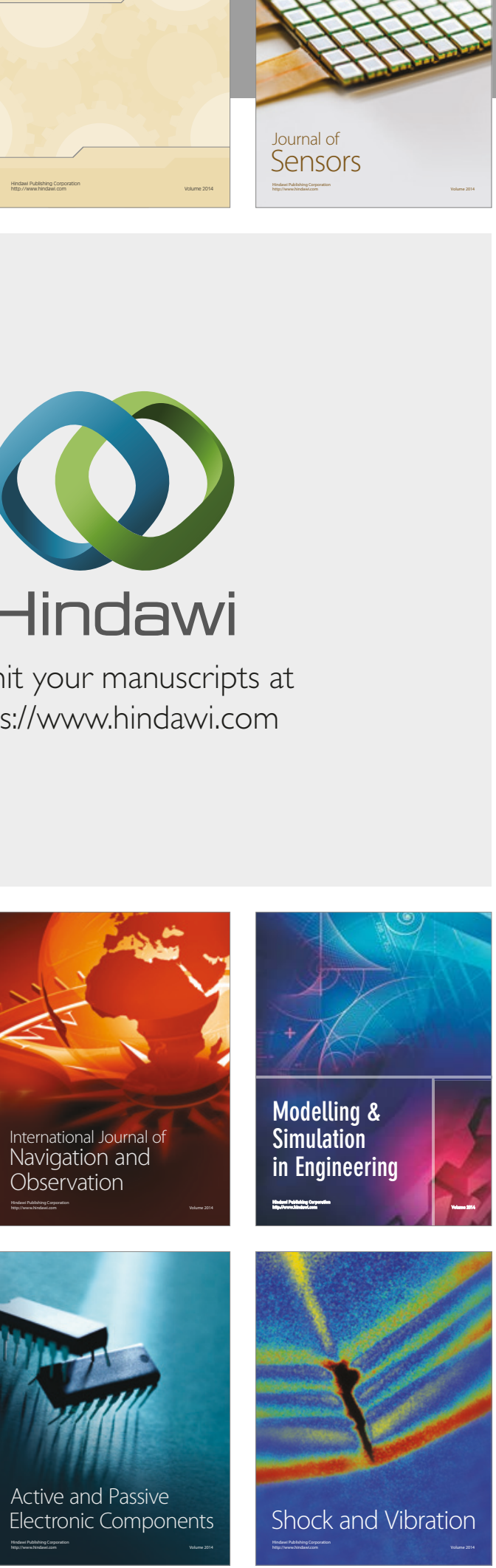
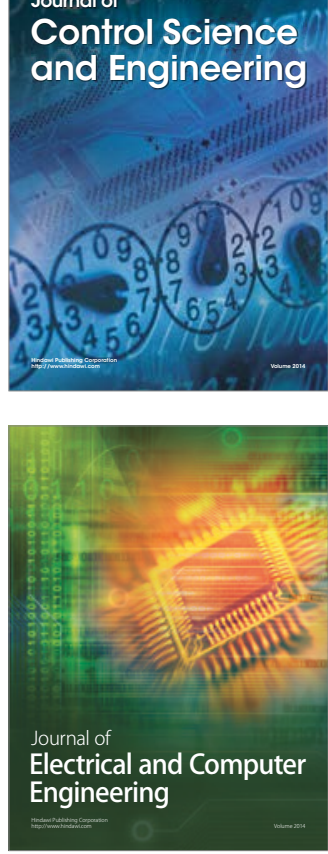

Distributed

Journal of

Control Science

and Engineering
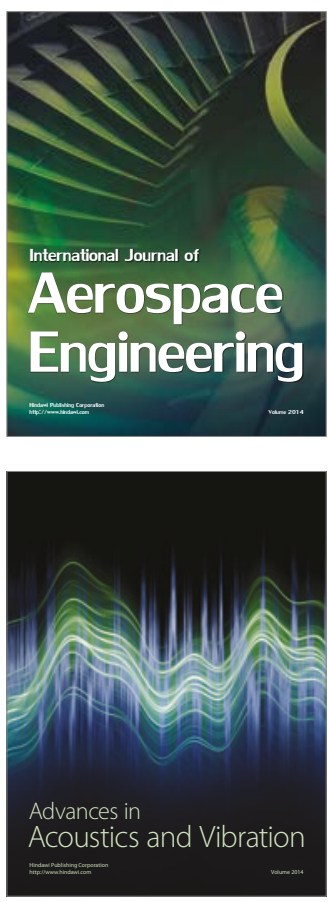

Sensor Networks 